\title{
Distribution of services within the call center and Covid 19 - a case study
}

\author{
ROBERT DANKIEWICZ \\ Department of Finance, Banking and Accounting \\ Rzeszow University of Technology \\ Al. Powstańców Warszawy 12, Rzeszow 35-959 \\ POLAND
}

DARIUSZ TWORZYDŁO

The Faculty of Journalism, Information and Book Studies

University of Warsaw

ul. Bednarska 2/4, 00-310 Warszawa

POLAND

ANNA OSTROWSKA-DANKIEWICZ

Department of Finance, Banking and Accounting

Rzeszow University of Technology

Al. Powstańców Warszawy 12, Rzeszow 35-959

POLAND

\begin{abstract}
The considerations presented in the paper concern the impact of Covid-19 on sales possibilities in the pre-paid system and development perspectives of the researched business entity. As part of its operations, this entity is responsible for the supply of fuel to nearly 4,500 customers conducting business operations throughout Poland. The study was carried out by means of the method of quantitative analysis of economic data. The acquired data constituted a closed set of 518479 contacts collected as a result of reporting the work of the call center department. The purpose of the paper is to analyze the impact of the Covid-19 pandemic on the possibilities of acquiring new customers by the entity that sells pre-paid fuels and the prospects for its future development. The analyzes allowed showing the relationship, before and after the introduction of socioeconomic restrictions, between the number of sales contacts made and their effectiveness. It was proved that lockdown caused changes in the scope of managing executive operations within the call center of the entity. This, in turn, affected operational and management decisions at both ownership and management levels.
\end{abstract}

Keywords: - Covid-19, economic crisis, call center as a sales channel, risk management

Received: May 13, 2020. Revised: October 21, 2020. Accepted: November 2, 2020.

Published: November 15, 2020.

\section{Introduction}

Changes that are taking place in the global economy, caused by the situation that arose as a result of the coronavirus pandemic, triggered diametrical and very damaging effects not only for economies themselves but also for a number of enterprises. Lack of mobility, inability to make purchases, and often even work, made that a number of people were locked up in their homes and apartments, which translated into a reduction or a total decline in revenues for companies. Entities such as hotels, restaurants, and the entire tourism industry experienced the effects of pandemic containment. The struggle for survival became a key and search area for management boards of companies which, in place of pro-developmental and strategic thinking, took up operational 
management of the effects of the crisis caused by COVID-19.

It was noticeable that the necessary restrictions imposed by governments in this situation hit the demand considerably. Some companies did not have sufficient funds to allow them to survive the first months of the pandemic. Thus, there were a number of falls. There was a change in the approach to work and a number of business entities switched to teleworking and providing online services, as well as conducting distance education.

It is very likely that components of the global economy such as companies will be forced to reevaluate their approach to strategic planning. Disturbed economically entities will be looking for new solutions for their sales activities, but the demand itself will also be rebuilt for a long time. Limiting the demand will depend on the extent and size of macroeconomic parameters such as the unemployment rate or inflation. There are companies and industries that will not only undergo changes but will experience balancing on the border of profitability, some will not repay loans, will not regain lost markets. The need to adapt to changes, but also the mere fact of their constant impact on companies, will be a key feature of the changes that are taking place in connection with the situation caused by the pandemic in the world.

This paper is an analysis of the effects of economic events caused by a coronavirus pandemic. On the example of a specific company, it indicates, in relation to micro and macro-economic parameters, how the global problem affected the economic situation, in particular the possibility of sales in the pre-paid system and the development perspectives of a business entity.

The aim of the article is to analyze the impact of the Covid-19 pandemic on the possibility of acquiring new customers by the entity selling prepaid fuels and the prospects of its future development. The article also shows the relationship, before and after the introduction of socio-economic constraints, between the number of established sales contacts and their effectiveness.

\section{Literature Review}

Economic crises and their impact on enterprises were widely described and thoroughly studied in the literature. One points out that various types of enterprises cope differently in times of economic crises, some perform better than others [1]. Research indicates that the crisis actually contributes to business failures by increasing their likelihood, but enterprises with higher levels of human capital and research and development are much better prepared to survive in adverse conditions [2]. It is also said that the phenomenon of crises and their effects is particularly important for enterprises from the SMEs sector, which are the basis of the economies of many countries. According to F. Eggers, SMEs are responsible for their small size, and crises additionally cause problems related to the availability of certain resources and liquidity problems, which results from the fact that clients often reduce or completely suspend expenditure $[3,4]$. Therefore, the most frequent victims of financial crises are precisely SMEs, because even small payment gridlocks can lead to their bankruptcy [5]. It can be noticed that as a result of the Covid-19 pandemic, enterprises are afraid of such problems and are changing their receivables management strategies [6]. On the other hand, other studies show that relatively small and young companies can have an advantage when it comes to growth in times of crisis, which may be due to their flexibility and small size. However, young companies that grew steadily during the time when the crisis was gone were disproportionately negatively affected by the effects of the crisis, when it already appeared [7].

In the literature, much of the research is devoted to how companies grow in times of crisis and what the results of their activities are. The majority of research concerns the global financial crisis that began in 2007. Research conducted in countries from different parts of the world shows that as a result of the crisis all industrial growth rates are falling, more adverse effects are manifested in sectors that are more dependent on external financing, and rely more on commercial loans [8]. Other studies provide evidence of significant differences in the profitability of enterprises in the pre-crisis and post-crisis periods [9]. In some countries, scientists show that individual sectors are at varying degrees of vulnerability to the effects of the crisis, but the economic crisis has the greatest impact on return on equity and employees' added value [10].In turn, according to some scientists, during the crisis, both investments in enterprises and the level of financial leverage are lower [11]. According to research, the recession that started in 2008, apart from obvious financial losses, also manifested in the fact that companies lost significantly on sales [12]. The economic crisis is reflected in the sharp decline in trade flows and the conditional decline in demand, which in turn leads to a decrease in production and reduction of employment [13] At the same time, it necessitates the monitoring of the risk of losing receivables, regardless of the area where the business is 
conducted [14]. In addition, financial crises seem to have a greater negative impact on diversified goods compared to overall export flows and persist even after taking into account the income effect [15]. Due to consumer spending constraints, the economic crisis often results in price increases, which is particularly pronounced in the food sector [16].

However, it is pointed out that despite many negative consequences, the financial crisis may have a positive impact on the company's financial results, its liquidity, and work efficiency. The crisis may also have an impact on the company's image, which also translates into its stability [17]. This means that enterprises are making much greater efforts to keep the results at the current level in the face of adverse environmental conditions [18] In addition, research suggests that enterprises can survive the crisis and even achieve good results by changing their marketing strategy [19].

The latest research conducted by scientists from various parts of the world also highlighted the first effects that the current pandemic already had and is likely to continue to exert on companies, their results, and their business strategy. At the moment, the impact of the crisis caused by the pandemic on the marketing sphere of enterprises is widely studied. Available studies report the very diverse effects of a coronavirus pandemic on enterprises and their business models. The conclusions of the analysis already indicate that even after the crisis some enterprises may remain in virtual interaction [20].

Crisis caused by a pandemic particularly affects the companies operating in the $\mathrm{B} 2 \mathrm{~B}$ sector, causing a decrease in sales, and thus intra-organizational tensions. This makes it necessary to change management practices. One often talks of the need for digital transformation [21, 22]. The literature also indicates that in a pandemic era it may be necessary to re-evaluate the business relationships of the company as a whole, as it may be an opportunity to find new partners who will be able to better meet the urgent, short-term needs of the company [23]. In a pandemic era, it also seems necessary to manage uncertainty appropriately. The current situation shows how important information uncertainty is, as well as the impact of direct communication and social media because uncertainty and various sources of communication caused panic and confusion [24]. The pandemic also gave companies an opportunity to switch to more authentic CSR, as well as to contribute to global environmental and social change [25]. With the help of CSR, it is possible to effectively build an external image, which impacts the reception of their brand during a crisis [26].

The pandemic also showed how important cooperation between enterprises was. However, after the end of the pandemic, business managers will also have to consider whether to continue working with competitors or resume operations under individual business models [27].

In spite of some positive effects of the pandemic, which gave companies an opportunity to look differently and re-evaluate certain decisions and the way of doing business, many of its negative effects cannot be ignored. As PWC points out, many companies face problems such as changes in the supply chain and associated changes in routes, delays, and thus the negative impact on customers. Some companies experience a drastic drop in sales that lead to financial problems. B2B companies, in turn, were particularly affected by restrictions on movement, which affected business relations, and regulations issued by governments often posed compliance challenges in some sectors [28]. As a significant proportion of world production takes place in China, there is a risk that the deterioration of the situation in this country will affect global value chains, and therefore other countries may also be affected by distortions in the Chinese market [29]. Simulations conducted by scientists show that in a worse scenario, a pandemic may have a negative impact on exports in all sectors and in most countries [30].

The COVID-19 pandemic that spread all over the world showed how important e-commerce is, especially at a time when direct contact with customers was very difficult or even impossible. It is pointed out that e-commerce can be an extremely relevant solution for consumers in times of crisis, it can also be a driving force for the economy and enterprises from the SMEs sector [31]. Studies show that the pandemic has increased the use of ecommerce and has also made this type of shopping a habit of customers [32]. Similar conclusions can be drawn from studies by other researchers, who indicate that although, due to the restrictions imposed during the pandemic, many businesses no longer exist, through huge disruptions to trade, communication, entertainment, and online shopping are experiencing unprecedented growth [33]. Studies show that the decrease in the availability of retail premises and the increase in health concerns have also been a huge stimulus to the growth of alternative distribution channels [34]. In addition, it is highly likely that increased sales via the internet will continue after the pandemic. Digitisation and technological progress result not only in 
technological innovation but also in changes in society and public awareness [35]. It should be noted, however, that business based on the use of alternative distribution channels, including the Internet, is not only a source of innovation and development. It is also a source of risk, which is linked to the growing number of threats in cyberspace [36]. Therefore, the current pandemic is the time when some enterprises struggle to survive, while others, thanks to the bold use of the opportunities offered by e-commerce, become market leaders [37]. Some relevant studies can be found in [38] and [39].

\section{Research methodology}

The paper contains the results of analyses related to the functioning of the call center of a company that is a fuel distributor for about 4,500 business entities in the Polish market based on the fuel card system over the years 2019 and 2020 in terms of changes caused by the coronavirus pandemic. This entity, like a number of others, was strongly influenced by the changes that took place in connection with the pandemic that happened in the world. The study was carried out by the method of quantitative analysis of economic data. In each similar case, the basis for the analysis is the data collected in the course of research. Similarly, in this situation, the data constituted a closed set collected as a result of reporting the work of the call center in the entity. The data was acquired and reported continuously at weekly intervals. All the collected data was processed for further analytical work. They were reviewed. Finally, after an initial verification and an assessment of the usefulness of data in terms of detailed inference, 518,479 contacts were subject to analytical work, of which 33,142 contacts referred to the period from the 12th week of the year, i.e. March 12 when restrictions described as "Lockdown" went into life. The diagram based on which reporting in the entity analyzed takes place is presented in figure 1 .

Figure 1. Reporting scheme - categories assigned to contacts

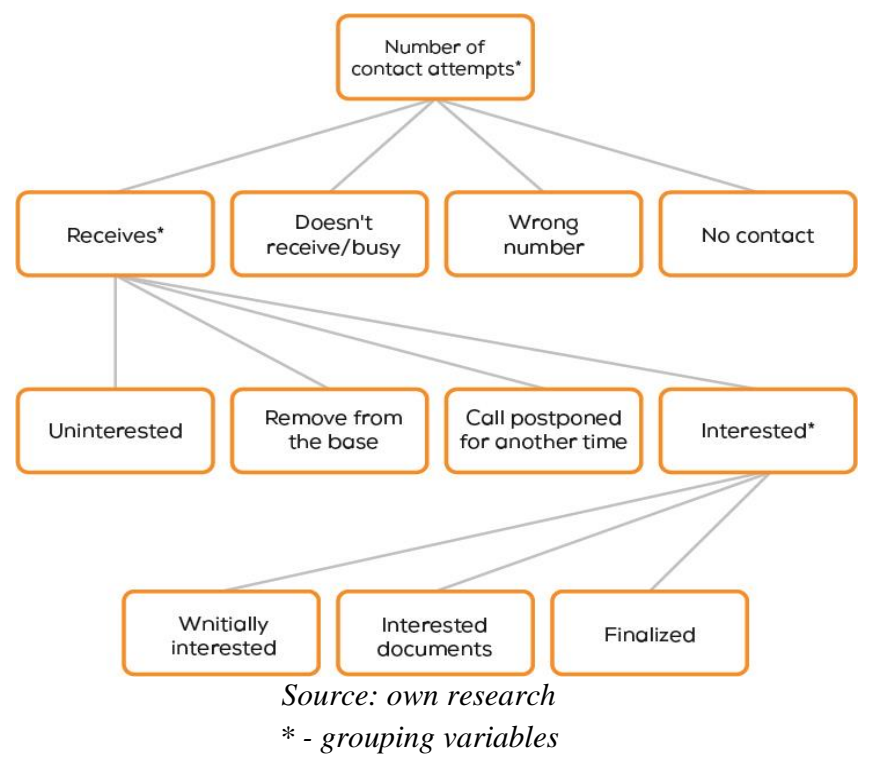

Each contact analysed was described using one of 12 categories. Nine categories have a disjoint charter, while three categories: "Number of attempted contacts", "Receives" and "Interested" are grouping variables.

In this way, a set was created, which was then subject to the quantitative analysis. As part of this inference, the accepted research hypotheses closely related to the effectiveness of the reported indicators were tested. These hypotheses are indicated in the next part which is devoted to data analysis. It can be seen that the weekly number of contacts from the call center is subject to fluctuations throughout the year. During the period under review, the largest decreases were recorded in the periods caused by public holidays:

- 1st week of the year 2019 (Christmas and New Year break),

- 18th week of the year 2019 (Easter),

- 25th week of the year 2019 (Corpus Christi),

- 33rd week of the year 2019 (holiday of the Polish Armed Forces, Assumption of the Blessed Virgin Mary),

- 52nd week of the year 2019 and 1st week of the year 2020 (Christmas),

- 15 th week of the year 2020 (Easter)

The analysis used not only an assessment of the frequency of phenomena but also correlations that allow a precise verification of the hypotheses. Frequency analysis allows to determine the distribution of responses in the sample. Its task is to present general information about the number and their percentage share in the examined sample. Correlation used in the analysis denotes the relationship between selected variables and is used to determine whether and what relationship occurs between two variables. The indicated methods of 
analysis are the basis for verification of the theses in this article and are used in its subsequent part.

\section{Data analysis obtained during the research process}

Lockdown has significantly changed the way companies operate. It has caused the necessity to reorganize processes and employee teams work. It caused the need for changes in the area of reaching, supporting and responding to customers' needs. It also brought about changes in the area of business relations at B2B level. Therefore, in order to obtain a broader knowledge of the changes that affected the economy on a micro scale, research was undertaken to indicate the areas important from the point of view of the surveyed entity. They are presented in this analysis.

As part of the research work, the initial hypotheses related to the effectiveness of the indicators were tested. The first hypothesis is expressed in the statement: the greater the number of contacts, the greater the number of calls received. The correlation coefficient in the period before the lockdown was Person's $r=0.954, p<0.001$, while in the lockdown period - Person's $r=0.972 ; p$ $<0.01$. Both before and after the lockdown, the calculated ratio showed almost full correlation ${ }^{1}$.

Another hypothesis relates to the theorem: the higher the number of calls received, the greater the number of interested parties, and here also statistically significant relationships were observed, with the factor before the lockdown being high Person's $r=0.551, p<0.001$, whereas after the lockdown the correlation was almost full - Person's $\mathrm{r}=0.956, \mathrm{p}<0.01$.

Finally, the above two analyses are confirmed in the test carried out as part of the hypothesis verification: the greater the number of contacts, the greater the interest. An increase in the correlation coefficient is seen from the average - Person's $r=$ $0.451, \mathrm{p}<0.001$ before the lockdown, to very high Persons $\mathrm{r}=0.890, \mathrm{p}<0.05$ in the lockdown cycle. The last initial hypothesis tested was the

\footnotetext{
${ }^{1}$ In the article, the method of interpretation of the correlation strength is based on the J.Guilford classification: $|\mathrm{r}|=0$ - no correlation

$0,0<|\mathbf{r}| \leq 0,1$ - faint correlation

$0,1<|\mathrm{r}| \leq 0,3$ - weak correlation

$0,3<|\mathbf{r}| \leq 0,5$ - average correlation

$0,5<|\mathrm{r}| \leq 0,7$ - high correlation

$0,7<|\mathbf{r}| \leq 0,9$ - very high correlation

$0,9<|\mathrm{r}|<1,0$ - almost full correlation

$|r|=1-$ full correlation
}

relationship expressed in the statement that the greater the number of contacts, the greater the number of transactions finalized. It turns out that before the lockdown there was a high correlation between these variables - Person's $\mathrm{r}=0.569, \mathrm{p}$ $<0.001$, while after the start of the lockdown the relationship between the variables was not significant. This means that in the analysed period broken into the period before the 12th week of 2020 and after the 12th week, when social limitations and very significant restrictions were introduced in the scope of business activity, the strength of the relationship between the number of contacts made and the number of received calls did not change and was of a character almost full correlation. In addition, the strength of the relationship between the number of contacts made and the number of people expressing an interest in the offer increased. The relationship between the number of received calls and the number of interested parties also grew up. In turn, the high correlation between the number of contacts and the number finalized before the lockdown and the time after the start of the lockdown ceased to have a statistically significant character.

The relationships expressed in the initial hypotheses translated into a number of further analytical activities aimed at obtaining information on how individual indicators featuring the effectiveness of customer acquisition through call center activities changed during the period under review.

Chart 1. The number of contact attempts broken down by categories. 


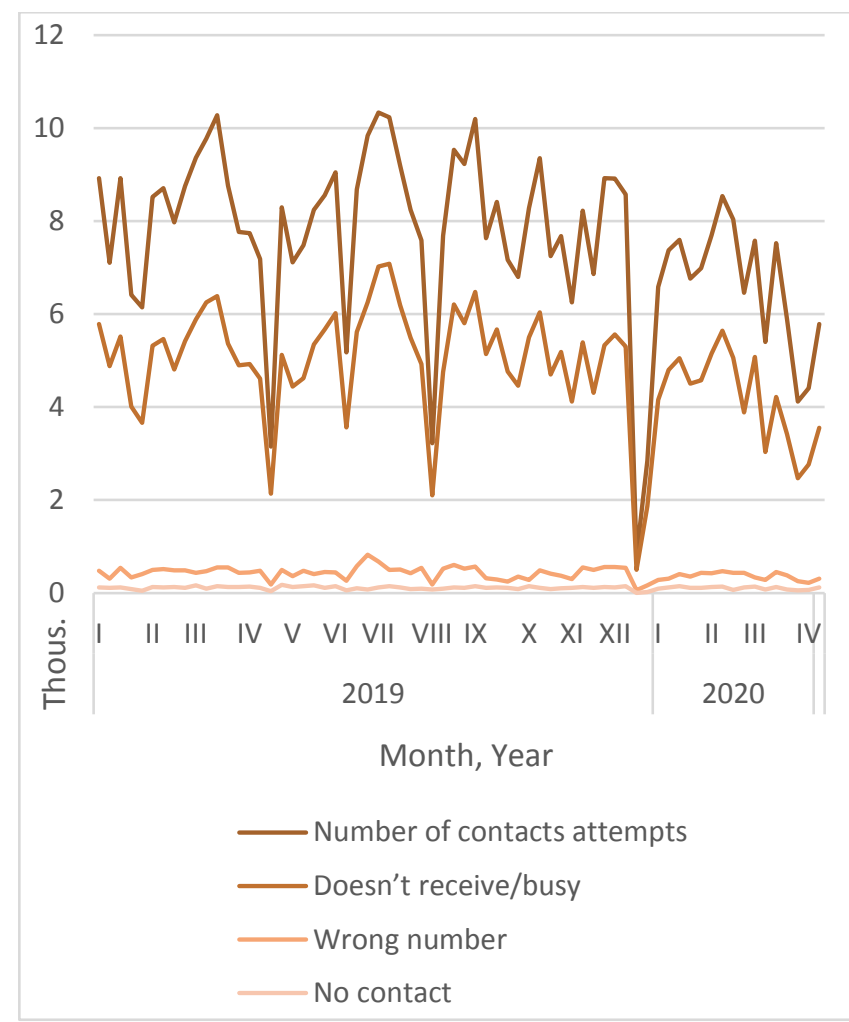

Source: own research

Chart 2. Percentage of contacts in specific categories relative to 'Number of attempts to contact"

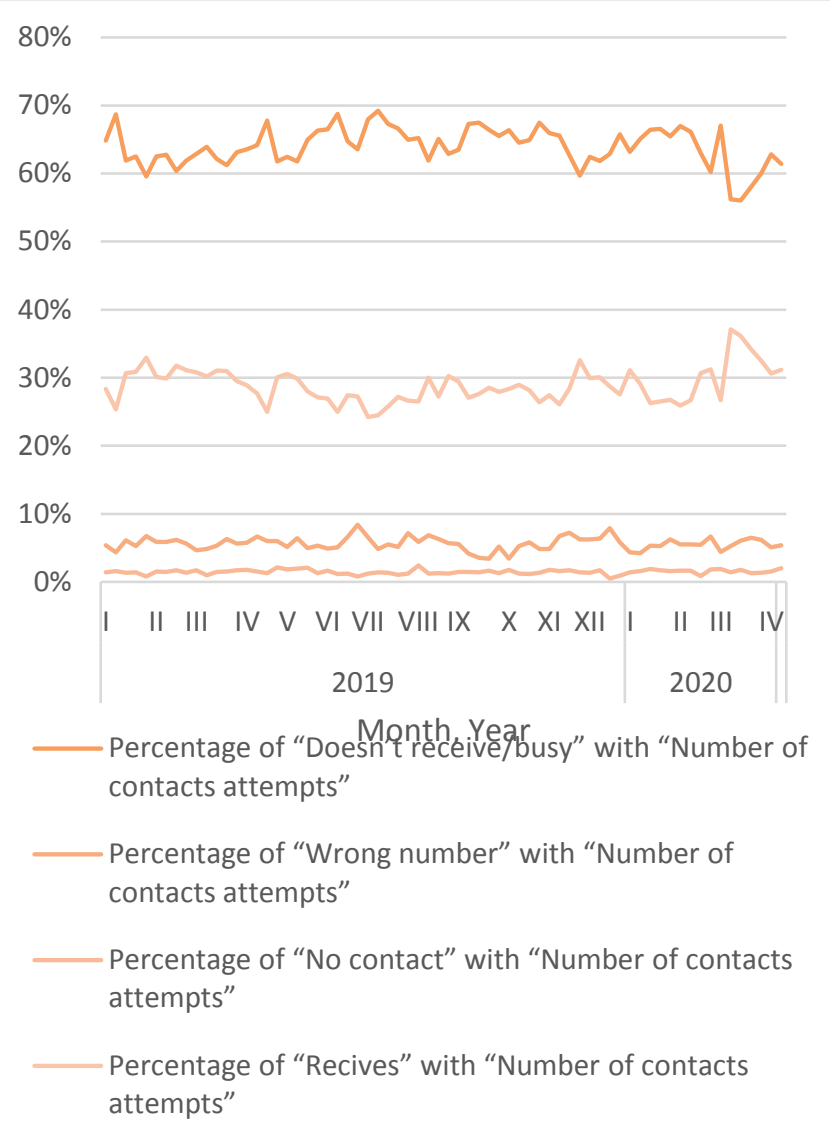

Source: own research

While the above correlations are based on absolute numbers and fluctuations in values depend on external factors such as holidays or decisions regarding the number of attempts made and the persons involved, the following analyses are based on interest rates, which means that regardless of the number contacts, the maximum will always be $100 \%$. This allows one to better observe what changes occur within a given indicator. The number of contact attempts broken down by categories is presented in chart 1 and the percentage of contacts in individual categories relative to the "number of contact attempts" in chart 2 .

Chart 3. Percentage of contacts in specific categories relative to "Receives" 


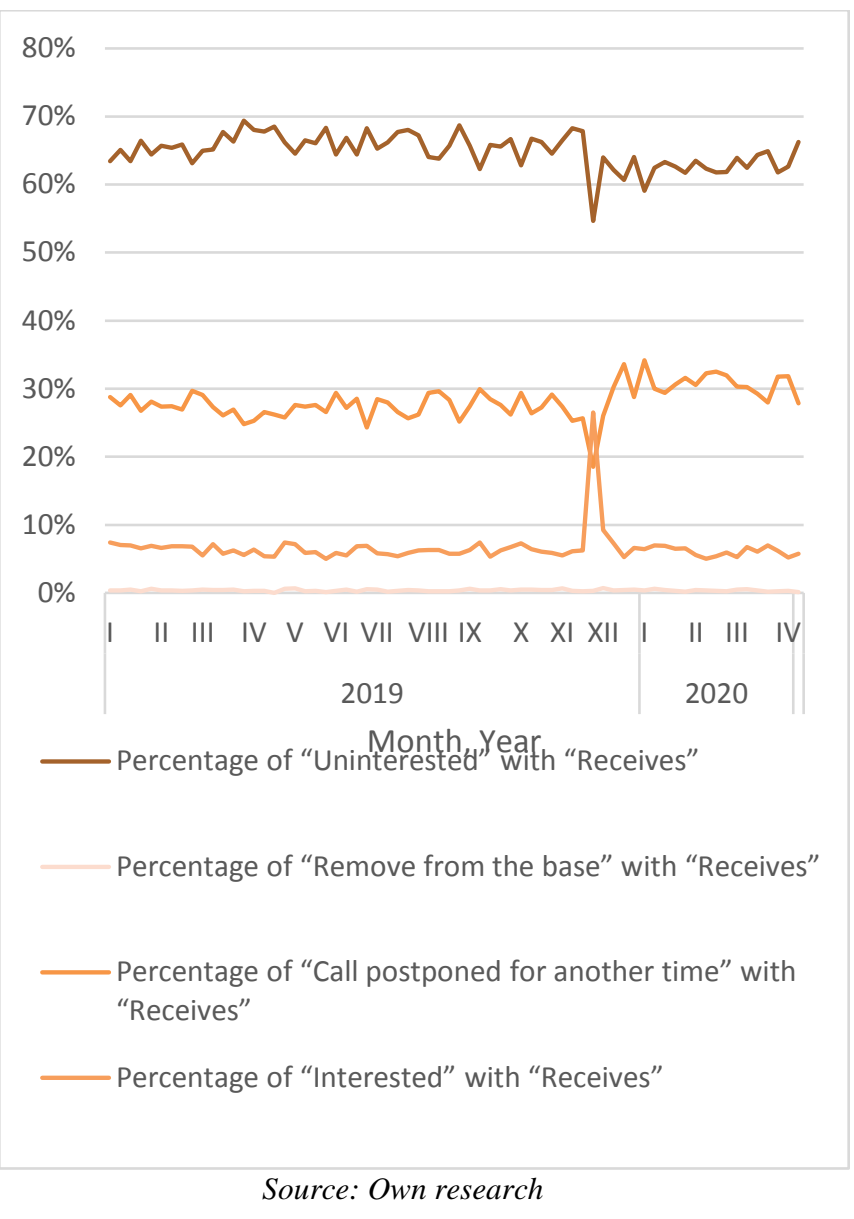

When comparing the period from the 12th week of 2020 to the previous period, one can notice a significant change in relation to the percentage of received and missed calls. An analysis of variance showed a significant decrease in the average percentage of the missed calls, from an average of $64.5 \%$ for the 63 weeks before the 12th week of 2020 , to $59.1 \%$ for the six weeks after the 12 th week of $2020(\mathrm{~F}=27.575 ; \mathrm{p}<0.001)$, simultaneously in the same period the percentage of received calls increased significantly from $28.4 \%$ to $33.6 \%$. ( $\mathrm{F}=$ $32,554 ; \mathrm{p}<0.001)$. The percentage of contacts in individual categories, including the "received" item, is presented in chart 3, while the "interested" item is shown in chart 4.

Lockdown made customers more accessible to companies that were willing to communicate with them. Permanent residence in homes and apartments resulted in a greater presence in the network, but also in an increased number of phone calls, not only on a personal level but also in the professional area. The social needs that had been fulfilled so far at work or with friends were replaced and supplemented by substitutes, among which were representatives of different companies calling to potential clients.
Chart 4. Percentage of contacts in specific categories relative to "Interested"

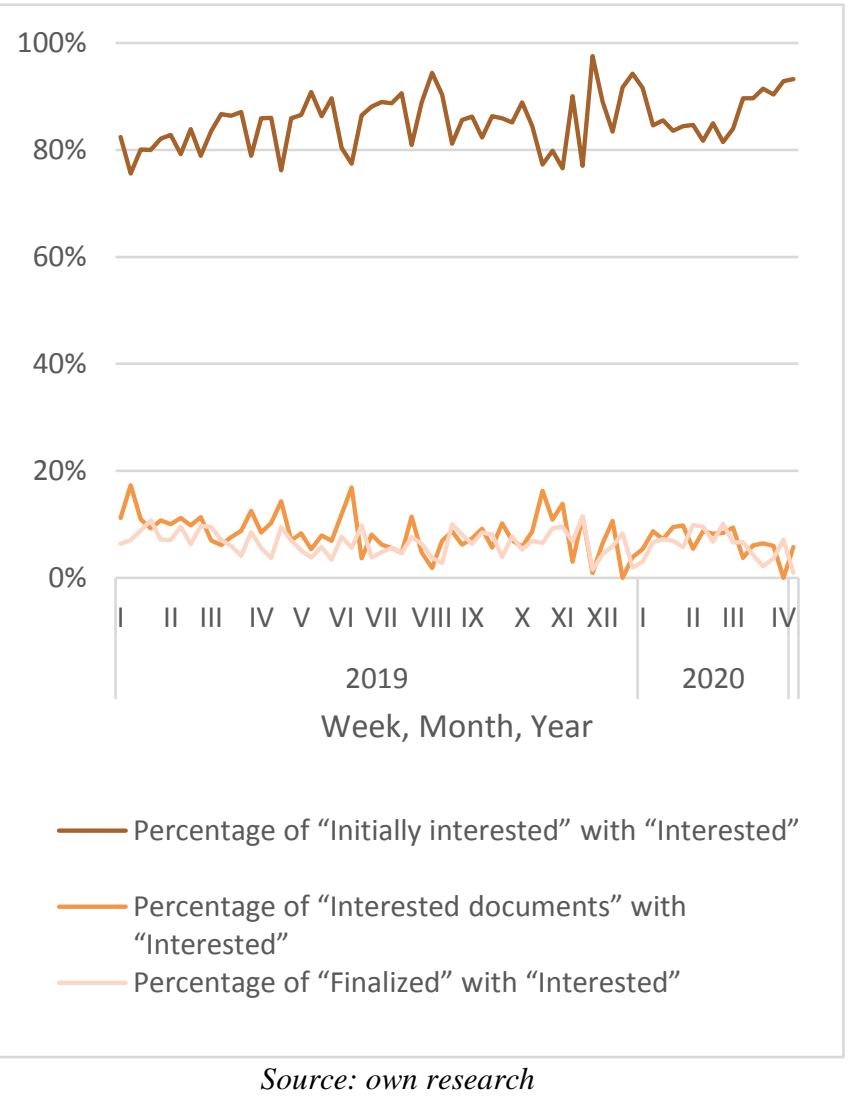

When comparing the period from the 12th week of 2020 to the previous period, one can notice a significant change in the percentage of those initially interested in relation to all those interested. An analysis of variance showed a significant increase in the average percentage of those initially interested relative to the general interest from an average of $84.8 \%$ for the 63 weeks prior to the 12 th week of 2020 , to $91.2 \%$ for the six weeks after the 12th week of $2020(F=10.722 ; p<0.01)$. At the same time, in the same period, there was a significant decrease in the percentage of interested persons to whom documents were sent relative to the total number of interested persons received from $28.4 \%$ to $33.6 \%(\mathrm{~F}=6.683 ; \mathrm{p}<0.05)$. Also, the percentage finalized in relation to all interested parties decreased significantly from $6.8 \%$ to $4.1 \%$. The percentage of people to whom documents were sent relative to those initially interested was also analysed. A significant decrease is observed from $10.2 \%$ to $5.1 \%(\mathrm{~F}=6.761 ; \mathrm{p}<0.05)$. The number of customers acquired weekly also decreased from 9.51 to $4.67(\mathrm{~F}=8.751 ; \mathrm{p}<0.05)$. It is worth noting that this indicator, unlike the above interest rates, is 
relative as it depends on the number of weekly contact attempts.

Figure 1. Reported categories including changes in the period after the introduction of lockdown relative to the period before the introduction of lockdown

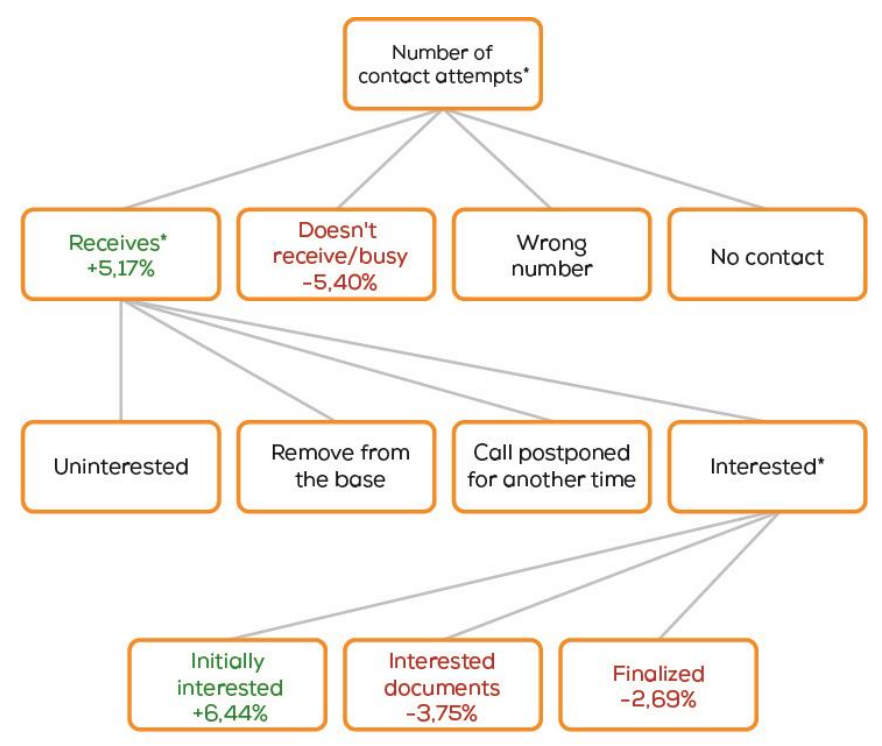

Source: own research

* - Grouping variables; The color indicates significant changes in the percentage together with the value by which the percentage changed during the lockdown relative to the period before the lockdown (100\% category one level higher e.g. for Initially interested $100 \%$ is Interested)

An important element that distinguished the lockdown situation was also the fact that the interest of customers in the products and services increased. A significant part of people who were deprived of the possibility of making purchases in the normal reality moved their activity to the network. They also became more susceptible to sales representatives calla. This change was made in a very fast and dynamic way. Nevertheless, during the lockdown, a decrease in the number of final decisions was observed, especially in companies. This was due to a situation of uncertainty that developed in companies, sudden drops in the area of orders, reduction of queries. The lack of decisionmaking was due to waiting. The boards of companies were not able to predict further changes that would appear in the business environment, because they were very fast, largely independent of companies, lying on the side of the business situation of other entities and the overall pandemic situation.
One can notice a drastic decrease in the number of relations connected with the introduction of restrictions on week 12th of 2020. The data, however, show that the reasons for this state of affairs should be seen in external conditions, not related to the relationship between a call center employee and a potential customer. The reduction in the number of connections may have been related to, among others with the reorganization of stationary work, the transition to remote work, or reduced availability of employees who were forced to take care of children due to the closing of schools and kindergartens. In the case of internal conditions, a clearly increased percentage of received calls could be observed. Intuitively, the situation should, first of all, intensify call center activities. At the same time, the number of those initially interested in the offer has increased, which in itself should be an incentive to intensify activities related to reaching customers. However, the number of interested persons to whom the document was sent and the number of acquired clients dropped.

The lockdown has brought about very significant changes in every aspect of social and economic life. It has triggered changes in purchasing processes. It evoked in people the need to look for substitutes for the activities that have been carried out so far but have been blocked by the state. To a great extent, the companies which faced at the same time increased interest in online shopping were not able to cope with this, due to the limitations and decrease in human resources available to the company. On the one hand, the restrictions and limitations caused positive changes, and on the other hand, the slower reactions to the increased demand have been observed.

Lockdown caused several different reactions. It triggered fear in people, but also the need to change their behaviour. This also applied to companies. The companies faced the need to change their methods and techniques of delivering goods to customers. They started to see the potential in remote work and changed the methods of establishing and maintaining contacts. They started to use new technologies and videoconferences on a massive scale. The changes in the methods of maintaining relations were not only significantly visible but also very dynamic. Some of the changes were short term. Some of the implemented principles were retained in companies and were eventually recognized as new standards and regulations. Companies had to adapt very quickly to the new reality. A similar situation applied to the entity analysed in this article. 
One can notice a statistically significant increase in the percentage of calls received during the lockdown relative to the period preceding the introduction of restrictions. This was due to the initial shock experienced by companies and the need to adapt to new realities. Changes in the area analysed were caused by the expectation of employee teams for the decisions of management boards, with a simultaneous observation of the socio-economic environment. It should be noted that at the same time the percentage of persons initially interested in the offer increased among the general interest. On the other hand, the percentage of acquired clients and people interested enough to receive application documents was reduced. Thus, there was a blockade even at the level of operational decisions, awaiting government decisions, but also a reluctance to take any risk, which consisted in limiting the incurrence of any external obligations, and such certainly included decisions that are discussed in this article.

\section{Conclusion and summary}

Based on the research, it can be concluded that there is a correlation between the activity in the scope of making management and operational decisions, and the shock experienced by the global economy. Changes and shifts in the area of purchasing decisions are noticeable.

Both before and after the lockdown, almost full correlation was observed, which allowed indicating that the greater the number of contacts, the greater the number of received calls. After the lockdown, an almost full correlation was also observed during the proof of the hypothesis that the higher the number of received calls, the greater the number of interested parties on the part of the entity. In the period analysed, which was divided into the time before and after the introduction of socio-economic restrictions, which translated into very serious restrictions on doing business, it was observed that the strength of the relationship between the number of contacts made and the number of received calls did not change and was almost fully correlated. However, the strength of the relationship between the number of contacts made and the number of people expressing interest in the offer presented during contacts increased. The relationship between the number of received calls and the number of interested parties also went up. In turn, the high correlation between the number of contacts and the number finalized before the lockdown and the time after the start of the lockdown ceased to have a statistically significant character. Thus, it was proved that the lockdown resulted in changes in the management of operations performed within the call center of the entity. This, in turn, affected operational and management decisions at both ownership and management levels.

Thus, on this one but important example, one can conclude about a clear correlation of coronavirusrelated events on activity and decisions made as part of business operations. Therefore, coronavirus forced quick and often key decisions, caused reactions that had an impact on the current situation of companies, and planning future activities.

The results of the research may have practical implications for salespeople in companies. The results highlight how important it is nowadays for companies to have the flexibility to adapt their operations and distribution channels to external conditions and customer needs. The research shows that in some difficult times, in crisis situations, it is necessary to make quick decisions that affect the current situation of companies and to plan future actions. Therefore, the research may make managers of companies aware of the importance of training their employees and ensuring that they are able to make effective decisions in crisis situations.

The most important novelty and added value of this work in relation to previous works in the literature is a very practical approach to presenting the effects of current events related to the covid-19 pandemic on business activities.

While previous studies have shown the impact of various types of crises on such aspects as the financial performance of companies or the development of individual financial indicators, this study shows how effective the distribution of services through the call centre sales channel was.

Thanks to data coming directly from an enterprise engaged in the distribution of fuel on the Polish market, it was possible to show how the way and speed of making purchase decisions by customers has changed, as well as how this has translated into the economic situation and development prospects of a particular business entity. The research is valuable because there are very few works in the literature that refer to the use of call centres as a method of service distribution in the economy.

These studies have the following limitations. Firstly, the research has been limited to the territory of Poland only, which gives a picture of customers' purchasing decisions and the effectiveness of the call centre as a method of distribution in one country only. Secondly, the research has focused on the distribution of one type of service. Focusing on more companies that distribute a wider range of 
services could give better results and allow more universal conclusions to be drawn for the economy as a whole. In addition, the use of a wider range of statistical methods could give slightly more accurate results. Nevertheless, the authors hope that the work has highlighted a number of interesting issues that will continue in the work of other authors.

Future research by the authors will focus, among other things, on studying the economic and financial impact that the crisis caused by the COVID-19 pandemic has had on the economies of individual countries and companies. The research will focus, in particular, on the impact of these events on enterprises from the SME sector, which are the basis of the economies of many countries. Moreover, in the future, the authors would like to examine how this situation will affect companies' access to financing opportunities for their activities.

\section{References:}

[1] Lee C.C., Chen M.P., Ning S.L., Why did some firms perform better in the global financial crisis?, Economic Research-Ekonomska Istraživanja, Vol. 3., Issue 1, 2017, pp. 13391366.

[2] Garcia Martinez M., Zouaghib F., Garcia Marcob T., Robinsona C., What drives business failure? Exploring the role of internal and external knowledge capabilities during the global financial crisis, Journal of Business Research, Vol. 98, 2019, pp. 441-449

[3] Eggers F., Masters of disasters? Challenges and opportunities for SMEs in times of crisis, Journal of Business Research, Vol. 116, 2020, pp. 199-208.

[4] Zimon G., Management strategies of working capital in Polish services providing companies, WSEAS Transactions on Business and Economics, Volume 17, 2020, pp. 225-230.

[5] Zimon G., Issues of financial liquidity of small and medium-sized trading companies: a case study from Poland, Entrepreneurship and Sustainability Issues 8(1), 2020, pp. 363-372.

[6] Zimon G., Dankiewicz R., Trade Credit Management Strategies in SMEs and the COVID-19 Pandemic - A Case of Poland, Sustainability, 12, 6114, 2020, pp. 1-16.

[7] Bartz W., Winkler A., Flexible or fragile? The growth performance of small and young businesses during the global financial crisis Evidence from Germany, Journal of Business Venturing, Vol. 31, 2016, pp. 196-21

[8] Moore T., Mirzaei A., The impact of the global financial crisis on industry growth, The
Manchester School, Vol. 84, No. 2, 2016, pp. 159-180.

[9] Notta O., Vlachvei A., The impact of Financial Crisis on firm performance in case of Greek food manufacturing firms, Procedia Economics and Finance, Vol. 14, 2014, pp. 454-460.

[10] Dolenc P., Grum A., Laporšek S., The Effect of Financial/ Economic Crisis on Firm Performance in Slovenia - A Micro Level, Difference-In-Differences Approach', Montenegrin Journal of Economics, Vol. 8, No 2, 2012, pp. 207-222.

[11] Muchtar D., Gusti Ngurah A, Mat Nor F., Ibrahim I, Jafarian M., The Financial Crisis Impact on Firm Performance, Financial Decision and Corporate Governance of Indonesia Listed Firms, Proceedings of the 1st Workshop on Multidisciplinary and Its Applications Part 1, 2019.

[12] Westergård-Nielsen N., Neamtu I., How Are Firms Affected by the Crisis and How Do They React?, IZA Discussion Paper, No. 6671, 2012.

[13] Čerović S., Pepić M., Petrović P., Čerović S., The impact of the global financial crisis on world trade, Economic Themes, Vol. 52, No. 1, 2014, pp. 13-32.

[14] Dankiewicz R., Monitoring ryzyka utraty należności W ubezpieczeni kredytu kupieckiego, Studia ubezpieczeniowe. Zarzadzanie ryzykiem i finansami, No. 182, 2011, pp. 50-59.

[15] Broll U., Jauer J., How International Trade is affected by the Financial Crisis: The Gravity Trade Equation, Dresden Discussion Paper in Economics, No. 3, 2014.

[16] Calvo-Porral C., Leighton Stanton J., LévyMangin J.P., Is the Economic Crisis Changing Marketing Strategies? Evidence from the Food Industry, Journal of Global Marketing, Vol. 29, No. 1, 2016, pp. 29-39.

[17] Tworzydło D., Zarządzanie $w$ kryzysie wizerunkowym. Metody, procedury, reagowanie, Difin, 2019, pp. 83-86.

[18] Madaleno M., Bărbuţă-Mişu N., The Financial Performance of European Companies: Explanatory Factors in the Context of Economic Crisis, Ekonomika, Vol. 98, No. 2, 2019, pp. 6-18.

[19] Notta O., Marketing strategies and performance during economic crisis, Proceedings of 2 nd International Conference on Contemporary Marketing Issues (ICCMI), ISBN: 978-960287-145-4, Volume 2, 2014, pp. 569-575.

[20] Ritter T., Pedersen C.L., Analyzing the impact of the coronavirus crisis on business models, 
Industrial Marketing Management, Vol. 88, 2020, pp. 214-224.

[21] Mora Cortez R., Jonhson W.J., The Coronavirus crisis in B2B settings: Crisis uniqueness and managerial implications based on social exchange theory, Industrial Marketing Management, Vol. 88, 2020, pp. 125-135

[22] Rapaccini M., Saccani N., Kowalkowski C., Paiola M, Adrodegarib F., Navigating disruptive crises through service-led growth: The impact of COVID-19 on Italian manufacturing firms, Industrial Marketing Management, Vol. 88, 2020, pp. 225-237.

[23] Obal M., Gao T., Managing business relationships during a pandemic: Conducting a $\mathrm{T}$ relationship audit and developing a path forward, Industrial Marketing Management, Vol. 88, 2020, pp. 247-254.

[24] Sharmaa P., Leungb T.Y., Kingshottc R.P.J., Davcikd N.S., Cardinali S., Managing uncertainty during a global pandemic: An international business perspective, Journal of Business Research, Vol. 116, 2020, pp. 188 192.

[25] He H., Harris L., The impact of Covid-19 pandemic on corporate social responsibility and T marketing philosophy, Journal of Business Research, Vol. 116, 2020, pp. 176-182.

[26] Tworzydło D, Gawronski S, Szuba P., Importance and role of CSR and stakeholder engagement strategy in polish companies in the context of activities of experts handling public relations. Corporate Social Responsibility Environmental Management 2020; pp. 1-7.

[27] Crick J.M., Crick D., Coopetition and COVID19: Collaborative business-to-business marketing strategies in a pandemic crisis, Industrial Marketing Management, Vol. 88, 2020, pp. 206-213.

[28] PWC, Considering the potential business impacts of the COVID-19 outbreak, 2020, available at:

https://www.pwc.com/m1/en/publications/covi d-19/considering-the-potential-businessimpacts-covid-19-outbreak.pdf (accessed on 12.06.2020).

[29] UNCTAD, Global trade impact of the coronavirus (COVID-19) epidemic, 2020, available at:

https://unctad.org/en/PublicationsLibrary/ditcin f2020d1.pdf (accessed on 12.06.2020).

[30] Maliszewska M., Mattoo A., van der Mensbrugghe D., The Potential Impact of COVID-19 on GDP and Trade: A Preliminary
Assessment, World Bank Group Policy Research working paper, No. WPS 9211, 2020.

[31] WTO, E-commerce, trade and the COVID-19 pandemic, 2020, available at:

https:/www.wto.org/english/tratop_e/covid19_ e/ecommerce_report_e.pdf (accessed on 12.06.2020).

[32] Bhatti A., Akram H., Basit H.M., Khan A.U., Raza Naqvi S.M., Bilal M., E-commerce trends during COVID-19 Pandemic, International Journal of Future Generation Communication and Networking, Vol. 13, No. 2, 2020, pp.1449-1452.

[33] Donthu N., Gustafsson A., Effects of COVID19 on business and research, Journal of Business Research, Vol. 117, 2020, pp. 284289.

[34] Pantano E., G. Pizzi, Scarpi D., Dennis C., Competing during a pandemic? Retailers' ups and downs during the COVID-19 outbreak, Journal of Business Research, Vol. 116, 2020, pp. 209-213.

[35] Płonka M., Jedynak T., Trynchuk V., Retirement behavior strategies: the attitudes of students from Poland and Ukraine towards the old-age risk, Problems and Perspectives in Management, 18(2), 2020, pp. 350-365.

[36] Strupczewski G., What Is the Worst Scenario? Modeling Extreme Cyber Losses. In: Linsley P., Shrives P., Wieczorek-Kosmala M. (eds) Multiple Perspectives in Risk and Risk Management. Springer Proceedings in Business and Economics. Springer, 2020.

[37] Deloitte, COVID-19 will permanently change e-commerce in Denmark, 2020, available at: https://www2.deloitte.com/content/dam/Deloitt e/dk/Documents/strategy/e-commerce-covid19-onepage.pdf accessed on 12.06.2020).

[38] Di Persio L., Honchar O., Multitask machine learning for financial forecasting, International Journal of Circuits, Systems, and Signal Processing, Vol. 12, 2018, pp. 444-451.

[39] Al Dhaheri H, Kim S., Kim S.Y., The Dynamics of Thalassemia Management in the United Arab Emirates, Interunational Journal of Biology and Biomedical Engineering, Vol. 12, 2018, pp. 151-164. 


\section{Contribution of individual authors to the creation of a scientific article (ghostwriting policy)}

\section{Author Contributions:}

Robert Dankiewicz, Anna Ostrowska-Dankiewicz responsible for organizing and conducting the study, systematizing data, reviewing the literature, developing content.

Dariusz Tworzydło - was responsible for the analysis, statistics, systematizing data, content development.
Creative Commons Attribution License 4.0 (Attribution 4.0 International, CC BY 4.0)

This article is published under the terms of the Creative Commons Attribution License 4.0

https://creativecommons.org/licenses/by/4.0/deed.en_US 